\title{
Does Migration Matter? Job Search Outcomes for the Unemployed
}

\section{Thomas P. Boehm, Henry W. Herzog, Jr., and Alan M. Schlottmann*}

From its beginnings, the United States has been characterized by a geographically mobile population. Historically, workers have sought new or better jobs in different localities as opportunity or necessity has dictated. Indeed, it is now generally accepted that the primary determinants of interregional labor force migration are differential employment growth and amenity-adjusted earnings (Greenwood 1975, Greenwood and Hunt 1984, Greenwood et al. 1991). However, a considerable body of empirical literature has evolved that questions the individual payoff to labor migration as well as the role played by migration in completed job search. More specifically, among the unemployed, to what extent does migration affect the likelihood of re-employment? As noted in the authors' recent survey on migration as spatial job search, there is no consistent empirical evidence for the unemployed that migration promotes favorable job search outcomes (Herzog, Schlottmann, Boehm 1993). ${ }^{1}$ This observation is particularly disturbing in that personal unemployment has been shown to significantly augment labor force migration (DaVanzo 1978, Schlottmann and Herzog 1981, Goss and Paul 1990).

In this study we investigate migration's effect on labor market transitions. Specifically, we explore transition rates out of unemployment (to employment) and from nonparticipation to active job search. To facilitate this, a multistate model of the hazard rate is developed and subsequently estimated. Our results strongly suggest that migration is both directly and indirectly associated with a successful transition to re-employment. Among nonparticipating workers, migration at a point in time is shown to be the primary determinant of re-entry into the labor force at a future date. Upon renewed participation and active job search, movers have a relatively higher likelihood of re-employment. This is an important result, for workers in our sample that remain out of the labor force "over time" have quite low re-entry probabilities. Among active job seekers, entry into employment is also directly enhanced through migration. In this regard, migration serves an important indirect role in successful employment transitions by moving workers to labor markets characterized by more favorable employment opportunities

\footnotetext{
*The authors are Professor of Finance and Professors of Economics, respectively, at the University of Tennessee, Knoxville. We wish to gratefully acknowledge our considerable debt to James J. Heckman and James R. Walker for advice and computational programs, and we wish to thank Timothy J. Bartik and Keith Ihlanfeldt for helpful comments on an earlier draft of this paper.

${ }^{1}$ Certainly there is little commonality to be observed in the literature surveyed (from 1964 to 1993 ) in either research design or findings. Most studies utilize binary variables to represent migration and/or employment within traditional regression analyses. We doubt that any of these studies has realistically imposed ceteris paribus conditions (on either selectivity factors or marginal benefits/costs of search) such that the migration variable effectively addresses the issue at hand. It is particularly unfortunate that the distinction between unemployment and nonparticipation in the labor force is blurred within these studies, and that local unemployment rates (which impact job success) are considered fixed rather than time-varying explanatory variables.
} 
(lower unemployment rates). Among both nonparticipants and unemployed members of the labor force, entry into employment is significantly enhanced through this aspect of migration.

The hazard function upon which this study is based is presented in the section below. Following a brief discussion of our research sample, estimates on the efficacy of migration as a job-search strategy are provided in Section II. Conclusions of the study follow in Section III.

\section{MODEL SPECIFICATION}

As noted above, we focus on factors, to include migration, that affect two specific transitions: the transition from nonparticipation to unemployment, and subsequently the transition from looking for work to being employed. In this regard, nonparticipation and unemployment are treated as two distinct states. ${ }^{2}$

Household heads are assumed to be in one of three possible "employment" states at any point in time, hereafter termed employed, searching (unemployed/actively looking for work), and nonparticipating (unemployed/not actively looking for work). Let $\mathrm{T}$ represent the time until the household head changes from the current employment state to one of the other two possibilities measured from some reference point. In this analysis the reference point will be the month in which the household head entered its current employment state. In addition, let $t$ represent calendar time measured from the same reference point. Thus, the likelihood that an individual remains in a particular employment state at calendar time $t$ is $P=\operatorname{Pr}(T>t)$. This probability must be determined indirectly from the hazard function $h$, the likelihood that $T>t$ given that the household attains a new employment status over a very small time interval defined from $t$ to $t+\Delta t$. The hazard rate in our analysis is a function of a set of time-varying exogenous variables. This function can be specified more formally as:

$$
\begin{aligned}
& h_{i}=\lim _{\Delta t \rightarrow 0} \frac{P_{i}(T>t \mid t<T<t+\Delta t)}{\Delta t} \\
= & \sum\left[\exp \left\{\alpha_{i_{n}}+\beta_{i_{n}} X_{t}+\frac{t \lambda_{\text {in }}-1}{\lambda_{1 \text { in }}} \cdot \gamma_{1 \text { in }}+\frac{t \lambda_{2 \text { in }}-1}{\lambda_{2 \text { in }}} \cdot \gamma_{2 \text { in }}+C_{\text {in }} \theta\right\}\right]
\end{aligned}
$$

where

$\beta_{\text {in }} X_{t}=$ estimated coefficients and corresponding time-varying and other variables that affect the likelihood of making the transition from employment status $i$ to either employment status $\mathrm{n}=\mathrm{j}$ or $\mathrm{k}$. 
$\lambda_{1 \text { in }}, \lambda_{2 \text { in }}=$ estimated (or in some cases, fixed) coefficients that deter$\gamma_{1 \text { in }}, \gamma_{2 \text { in }}$ mine the effect of time in a given state of employment, $i$, on the likelihood of making a transition to a new employment status, $n=j$ or $k$.

$\mathrm{C}_{\mathrm{in}} \theta=$ transition-specific unobserved heterogeneity component $(\Theta)$ with estimated parameter $\left(C_{i n}\right)$.

The above specification represents the unrestricted hazard function based upon the Heckman-Singer model (Heckman and Singer 1985, Ch. 2). The hazard $h_{i}$, which depends upon exogenous variables, represents the rate at which transition could occur in the next instant given that a change in employment status had not occurred by time $t$. In this respect, it is possible to consistently estimate the parameters of the hazard (including the transition-specific factor loadings $\mathrm{C}_{\text {in }}$ ) and the population distribution of the unobservables while allowing for nontrivial spell-specific duration dependence. ${ }^{3}$ After pretesting, the Weibull form of the hazard was employed with a correction for unobserved heterogeneity following the nonparametric strategy proposed by Heckman and Singer. ${ }^{4}$ From this estimated hazard function the probability of exiting a particular employment state can be calculated as:

$$
P=\sum_{k=1}^{m} \int_{\alpha_{k-1}}^{\alpha_{k}} h(t) \exp \left[-\int_{0}^{t} h(u) d u\right] d t
$$

where

$$
\begin{aligned}
& m=\text { the total number of time periods (months) in } T . \\
& \alpha_{k}=k / m .
\end{aligned}
$$

At any time, the household head might exit from a given state of employment to one of two other states. For example, an individual who is unemployed and looking for work will either become employed, or eventually discouraged and subsequently a nonparticipant. The specific cumulative likelihoods of such transitions can be calculated (deleting for expositional clarity the scalar unobservable) as:

$$
P_{32}(t)=\sum_{t=1}^{m}\left\{\frac { e ^ { \beta _ { 3 2 } X _ { t } } } { e ^ { \beta _ { 3 2 } X _ { t } + } e ^ { \beta _ { 3 1 } X _ { t } } } \cdot \left(\left[1-\exp ^{-l e \beta_{32} X_{t} \cdot H\left(\alpha_{t}, \gamma_{32}\right)+e \beta_{31} x_{t} \cdot H\left(\alpha_{1}, \gamma_{31}\right) !}\right]\right.\right.
$$

\footnotetext{
${ }^{3}$ Although the theoretical importance of unobservable sources of heterogeneity has long been recognized, most empirical studies preclude its consideration. In the results presented below, spurious negative duration dependence is generated in the nonparticipation state if population heterogeneity is not accounted for. For one of the best discussions of population heterogeneity in the context of duration models, see Devine and Kiefer (1991, 98-99). ${ }^{4}$ Other forms specified for the hazard function were the exponential, Gompertz, and quadratic. It is of interest to note that, although the Weibull was determined to provide the best fit, results derived from other specifications did not substantially alter the results (except, of course, for the exponential hazard). For a detailed discussion of the way to select the "best" model, see Heckman and Walker $(1986,1987)$ [for detailed computations see the 1986 version]. As noted by Devine and Kiefer $(1991,158)$ such specification checks, although uncommon, are essential. In this regard, see the excellent analysis of Trussell and Richards (1985).
} 
6 Boehm, Herzog, Schlottman The Review of Regional Studies 1998, 28(1)

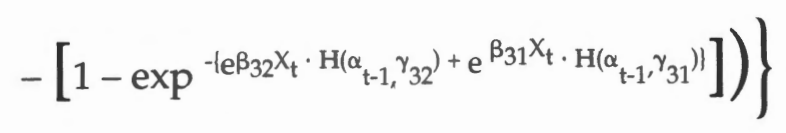

where:

$$
\begin{aligned}
& P_{21}(t)=\sum_{t=1}^{m}\left\{\frac { e ^ { \beta _ { 2 1 } x _ { t } } } { e ^ { \beta _ { 2 1 } x _ { t } + } e ^ { \beta _ { 2 3 } x _ { t } } } \cdot \left(\left[1-\exp ^{\left.-l e \beta_{21} x_{t} \cdot H\left(\alpha_{t}, \gamma_{21}\right)+e \beta_{23} X_{t} \cdot H\left(\alpha_{1}, \gamma_{23}\right) \mid\right]}\right.\right.\right.
\end{aligned}
$$

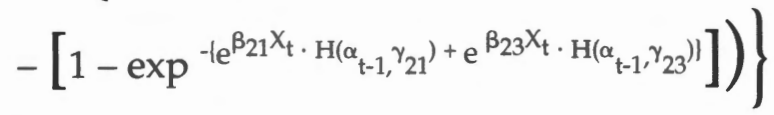

$$
\begin{aligned}
& 1=\text { employed } \\
& 2 \text { = searching } \\
& 3=\text { nonparticipating }
\end{aligned}
$$

$\beta_{\mathrm{ij}} \mathrm{X}_{\mathrm{t}}=$ vector of coefficients showing the effect of time-varying and other variables on the likelihood of transition from employment status $i$ to employment status $j$, multiplied by the corresponding variable values in period $t$.

$$
\begin{aligned}
& H\left(\alpha_{t}, \gamma\right)=\frac{\alpha_{t}^{\gamma+1}}{\gamma+1} \text { for the Weibull hazard. } \\
& \alpha_{\mathrm{t}-1}=-\ln \left[1-\left(\mathrm{P}_{\mathrm{ij}, \mathrm{t}-1} / \mathrm{A}_{\mathrm{ij}}\right)\right] /\left[\mathrm{D}_{\mathrm{ij}}+\mathrm{D}_{\mathrm{ik}}\right] \\
& A_{i j}=e^{\beta_{i j} X_{t}} /\left(e^{\beta_{i j} X_{t}}+e^{\beta_{i j} X_{t}}\right) \\
& D_{i j}=\left[\left(e^{\beta_{i j} X_{t}}\right) /\left(\gamma_{i j}+1\right)\right]^{\Phi_{i j} ;} D_{i k}=\left[\left(e^{\beta_{i j} X_{t}}\right) /\left(\gamma_{i k}+1\right)\right]^{\Phi_{i k}} \\
& \Phi_{\mathrm{ij}}=1 /\left(\gamma_{\mathrm{ij}}+1\right) ; \Phi_{\mathrm{ik}}=1 /\left(\gamma_{\mathrm{ik}}+1\right) \\
& \alpha_{\mathrm{t}}=\alpha_{\mathrm{t}-1}+1 / \mathrm{m}
\end{aligned}
$$

In the subsequent empirical analysis, we derive the impact of migration and other independent variables (including time within a given state) on the cumulative probability of a household head making one of these two transitions.

Job-search theory generally supports a negative causal relationship between migration and duration of search unemployment. According to Schwartz (1976), workers face a tradeoff between the radius of search undertaken and time to find an acceptable wage offer. In this regard, expansion of the search radius increases the number of available jobs (within a given occupation), thereby reducing search time. To the extent that migration is a proxy for search radius, search time and migration are negatively associated. In addition, since migration is costly, 
destination reservation wages may be lowered (particularly for the unemployed) such that relocation costs are recouped more quickly through re-employment. On the other hand, Seater (1979) notes that expanding the radius of search (of which migration is the extreme) may increase search duration proportionally more than the likelihood of finding an acceptable job offer. In any regard, empirical evidence (beginning with the case histories of Lansing and Mueller 1967) strongly suggests that migration streams are directed toward areas with expanding job opportunities. However, empirical analyses of such migration effects are often static in nature and draw upon survey (micro) data with retrospective questions extending back as many as five years.

\section{ECONOMETRIC ESTIMATES}

\section{DATA}

Longitudinal microdata for the study was drawn from the (corrected) 1987 panel of the Survey of Income and Program Participation (SIPP). (For a detailed description, see U.S. Department of Commerce, 1991). The monthly labor market histories utilized here covered the 26-month period from January 1987 to March $1989 .{ }^{5}$ In order to focus upon workers with a strong attachment to the labor force, the research population was confined to heads of households between the ages of 20 and 60. Based upon these restrictions, the research sample consists of 3,814 household heads and 6,096 total spells (in months) of employment, job search and nonparticipation over the 26 -month period. ${ }^{6}$

It is assumed that employment transitions are a function of human capital and other personal and locational characteristics as outlined in Polachek and Siebert (1993). Individual and family characteristics were drawn from SIPP and include age, education, marital status, race, presence of a work-limiting disability, gender and the presence of school-age children, receipt of unemployment compensation, and the level of household income (the latter two measured in dollars). Migration, the major test variable, was also included and represents an interstate move. Finally, for each state the monthly series of unemployment rates for the 26month period was included as a measure of local economic conditions (obtained from the U.S. Department of Commerce). In this regard, these unemployment rates are consistent with time-varying independent variables (above) obtained from SIPP, and as such effectively "fix" state economic conditions at the time employment transitions are being considered.

${ }^{5}$ For interview purposes, sample households within SIPP are divided into four subsamples (or rotations). Rotation 2, which ended in January 1989, was not utilized. January 1987 represents the first "overlap" month common to all rotations.

${ }^{6}$ In this regard, 1,819 spells were observed in which the household head was a nonparticipant. For those households in which the head ultimately made a transition to actively looking for work, the average duration of nonparticipation was 4.94 months. In addition, there were 1,005 observed spells in which a household head was actively looking for work, 60.6 percent of which resulted in a transition to employment. Finally, the average duration for all 1,005 spells of active job search was 2.53 months.

'Education, race, marital status-gender, presence of school-age children, disability status, and migration are represented by categorical variables within the empirical analysis. 


\section{ESTIMATES}

Table 1 presents parameter estimates relating to the two transitions of interest. Notice among these estimates that educational attainment significantly affects labor market outcomes. In this regard, heads of households with low levels of education (the two categories of no high school and some high school) are significantly less likely than high school graduates to exit nonparticipation and begin active job search (see column 1). By contrast, higher levels of education (the categories of some college and college graduate) increase the probability of both active job search and employment (columns 1 and 2, respectively). Where significant, other variables are consistent for the most part with previous work based upon either static analyses or labor market histories (Polacheck and Siebert 1993, Devine and Kiefer 1991, Ch. 6). ${ }^{8}$ However, the insignificance of age in the searching to employment transition (column 2) is unexpected.

There has been considerable attention, at the theoretical level, devoted to partitioning the effects of heterogeneity and state dependence on the length of nonparticipation and unemployment spells. It is interesting to note in this regard that unobserved heterogeneity, $C_{\text {in }}$ in Table 1, is an important determinant of both job search transitions. Our results suggest that estimates of duration dependence for the length of nonparticipation depend critically upon the inclusion of unobserved heterogeneity within the model. ${ }^{9}$

As shown in Table 1 (first column), migration is the primary event augmenting the likelihood that nonparticipants enter active job search. Further, if a one-tailed test for the significance of migration among active job seekers (second column) is accepted (Herzog, Schlottmann, Boehm 1993), then migration increases the probability of entry into employment for such workers. In addition, migration can indirectly influence labor market outcomes, in a positive fashion, if heads of households move to states characterized by low relative unemployment rates. As discussed below, this positive impact of migration occurs within our sample. In this regard, note in Table 1 that the probability of a nonparticipant beginning active job search and, subsequently, securing employment is a decreas-ing function of the monthly unemployment rate (columns 1 and 2, respectively). The importance of these results stems, in part, from the implied impact of time in state on labor market transitions.

Table 2 presents the implied cumulative probabilities of transition over time based upon the parameter estimates discussed above. As shown in Table 2 (first column), the likelihood of exit from nonparticipation to active job search is quite low. Although such cumulative probabilities are significantly higher for unem-

\footnotetext{
${ }^{8}$ Although two-state models of nonemployment-employment have provided some curious results, there is evidence of at least weak negative duration dependence for the transition to employment (Devine and Kiefer, 1991, Chapter 6). The evidence for three-state models is mixed. As shown in Table 1, our estimates suggest insignificant duration dependence for the transition from nonparticipation to searching but positive dependence for the transition from searching to employment. This may reflect, in part, the fact that the national unemployment rate continuously declined by 15 percent from 6.2 percent to 5.3 percent over the period of the study.

'If unobserved heterogeneity is ignored, then estimates in Table 1 would show strong negative duration dependence for the nonparticipation state (estimated parameter of -.510 with [absolute] asymptotic $t$-value of 7.72 ).
} 


\section{TABLE 1}

Parameter Estimates for Job Search Transitions Over the Period January 1987-March 1989a

\begin{tabular}{|c|c|c|}
\hline Variable & $\begin{array}{c}\text { Nonparticipation }= \\
\text { Searching } \\
\text { (1) }\end{array}$ & $\begin{array}{l}\text { Searching } \Rightarrow \\
\text { Employed } \\
(2)\end{array}$ \\
\hline Constant & $\begin{array}{c}2.793 \\
(4.401)\end{array}$ & $\begin{array}{c}4.387 \\
(12.363)\end{array}$ \\
\hline Age $^{b}$ & $\begin{array}{l}-0.0925 \\
(1.670)\end{array}$ & $\begin{array}{l}-0.047 \\
(1.447)\end{array}$ \\
\hline
\end{tabular}

Education ${ }^{\mathrm{C}}$

\section{No High School}

$-1.225$

(4.426)

$-0.194$

Some High School

$-0.394$

(1.914)

Some College

0.285

(1.885)

College Graduate

0.595

(2.440)

(Or Post-Graduate)

0.459

(2.069)

0.201

(1.837)

0.170

Nonwhite

Incur Disability

$-0.162$

in a Specific Month

Single Female with

No School-Age

Single Female with

Single Male

Household Income

Unemployment

Compensation

Migrate

0.711

Monthly

Time in State

absolute value of asymptotic normal statistics in parentheses. Negative log likelihood signifcant at the 0.01 level. As discussed in text, 3,814 heads of households and 6,096 spells of employment, job search, and nonparticipation comprise the data set. Coefficients presented for the two transitions above were estimated within a model inclusive of all possible transitions.

'Measured in decades (mean sample value of 4.79).

'The (omitted) reference category is high school graduate.

'The (omitted) reference category for marital status-gender is married heads of households.

Our sample did not contain single males who described themselves as heads of households with school-age children present.

-Measured in $\$ 1,000$ units.

Monthly state unemployment rates expressed as decimals.

sUnobserved heterogeneity was estimated as a non-parametric mixing distribution (given no apriori information on the specific functional form). The estimates shown in Table 1 are based on a computational form of the likelihood function with two points of support. 
ployed heads of households actively seeking work (second column), marginal benefits of continued search beyond the fifth or sixth month are relatively small.

TABLE 2

Effect of Time in a Given State on the Likelihood of Transition (Cumulative Probability)

\begin{tabular}{ccc}
\hline Month & $\begin{array}{c}\text { Nonparticipation } \\
\text { Searching } \\
(1)\end{array}$ & $\begin{array}{c}\text { Searching }= \\
\text { Employed } \\
(2)\end{array}$ \\
\hline 1 & 0.023 & 0.224 \\
2 & 0.037 & 0.453 \\
4 & 0.050 & 0.617 \\
5 & 0.061 & 0.708 \\
6 & 0.071 & 0.752 \\
9 & 0.080 & 0.772 \\
12 & 0.103 & 0.791 \\
\hline
\end{tabular}

Independent variables other than time held constant at their mean values (in the first month).

The direct and indirect impacts of migration on job search transitions are provided in Table 3. As shown, migration dramatically stimulates active job search among nonparticipants, and is the only variable in Table 1 to have such an impact. This results appears consistent with case studies of the long-term unemployed, in which a significant life-event (to include new job training) is often associated with ending nonparticipation (Sullivan 1978, Zippay 1991). In addition, migration has a positive impact on the employment prospects of active job seekers (ceteris paribus). In this regard, a fundamental issue for all migrants is the extent to which they select destination labor markets with more favorable job opportunities.

\section{TABLE 3}

Impact of Migration on Job-Search Transitions

\begin{tabular}{|c|c|c|}
\hline Event & $\begin{array}{c}\text { Nonparticipation - } \\
\text { Searching } \\
\text { (1) }\end{array}$ & $\begin{aligned} & \text { Searching } \\
& \Rightarrow \text { Employed } \\
&(2)\end{aligned}$ \\
\hline \multicolumn{3}{|c|}{$\begin{array}{l}\text { Cumulative Probability } \\
\text { (All Other Variables)a }\end{array}$} \\
\hline First month & 0.023 & 0.224 \\
\hline Twelfth month & 0.122 & 0.794 \\
\hline \multicolumn{3}{|l|}{ Migration: ${ }^{\mathrm{b}}$} \\
\hline $\begin{array}{l}\overline{\partial \operatorname{Pr} \mid \partial X_{i}} \\
\text { Percent Change }\end{array}$ & Percent Change & $0.088^{c}$ \\
\hline First month & 395.6 & 39.3 \\
\hline Twelfth month & 74.6 & 11.1 \\
\hline \multicolumn{3}{|c|}{ Lower Unemployment Rate: ${ }^{\text {d }}$} \\
\hline $\begin{array}{l}\partial \operatorname{Pr} \mid \partial X_{i} \\
\text { Percent Change }\end{array}$ & .046 & .044 \\
\hline First month & 200.0 & 19.6 \\
\hline Twelfth month & 37.7 & 5.5 \\
\hline
\end{tabular}

"Cumulative probability with independent variables at their mean values. See Table 2.

'Evaluated as a 0 to 1 event rather than at mean value. With migration a dichotomous variable, we present the change in probability rather than an elasticity.

'Based upon a one-tailed significance test (see Table 1).

'Represents a change of one standard deviation below the mean value. This is consistent with the "average" improvement for a migrant. 
There is little dispute that information on potential destinations is an important determinant of migration. Whether migrants collect enough information for optimal job search in destination regions is a more difficult question to address (Herzog, Schlottmann, Boehm 1993). As shown in Table 3, movement to more favorable labor markets (with lower unemployment rates) significantly enhances job search outcomes. In our sample, 59 percent of both nonparticipants and searching heads of household who do move, consistently do so to a state with an unemployment rate below the sample average for the month of the move. The average reduction in unemployment rate (destination state - origin state) is 16.9 percent. Given such results, it seems reasonable to suggest that state employment services target job-search assistance on an enhanced spatial basis.

\section{CONCLUSIONS}

In this study we investigate whether migration among individuals without jobs leads to enhanced employment opportunity. Specifically, we analyze transition rates out of unemployment (to employment) and from nonparticipation to active job search. Our results suggest that migration is a significant factor in improving the likelihood of reemployment, particularly to the extent that it encourages heads of households not in the labor force to renew job search. With both nonparticipants and active job seekers moving, on average, to destination labor markets with lower rates of unemployment, such mobility further enhances post-move job success.

Clearly, our results suggest that a reassessment of the job-matching programs associated with state employment services is in order. For the unemployed, reliance on "family, friends, and relatives" for job information is insufficient (the low exit rates out of nonparticipation a case in point). Recently, their has been bipartisan support for what Labor Secretary Robert Reich has termed a "reemployment insurance program," whereby unemployed workers would be extended retraining and job-search assistance expanded on a spatial basis to include migration. Our results suggest that expanding worker mobility and job information in this manner should prove to be an effective policy instrument.

\section{REFERENCES}

DaVanzo, Julie. "Does Unemployment Affect Migration? Evidence from Microdata." Review of Economics and Statistics, Vol. 60, 1978, 504-14.

Devine, Theresa J., and Nicholas M. Kiefer. Empirical Labor Economics: The Search Approach. New York: Oxford University Press, 1991.

Goss, Ernest, and C. Paul. "The Impact of Unemployment Insurance Benefits on the Probability of Migration of the Unemployed." Journal of Regional Science, Vol. 30, 1990, 349-58.

Greenwood, Michael J. "Research on Internal Migration in the United States: A Survey." Journal of Economic Literature, Vol. 13, 1975, 397-433. 
Greenwood, Michael J., and Gary L. Hunt. "Migration and Interregional Employment Redistribution in the United States." American Economic Review, December 1984, Vol. 74, 957-69.

Greenwood, Michael J., Gary L. Hunt, Dan S. Rickman and George I. Treyz. "Migration, Regional Equilibrium, and the Estimation of Compensating Differentials." American Economic Review, December 1991, Vol. 81, 1382-90. Heckman, James J., and Burton Singer. Longitudinal Analysis of Labor Market Data. New York: Cambridge University Press, 1985.

Heckman, James J., and J. Robert Walker. "Using Goodness of Fit and Other Criteria to Choose Among Competing Duration Models: A Case Study of Hutterite Data." University of Chicago, (Revised) December 1986. [A published version appears in Sociological Methodology, Vol. 17, 1987, 247-307.]

Herzog, Henry W., Jr., Alan M. Schlottmann, and Thomas P. Boehm. "Migration as Spatial Job-Search: A Survey of Empirical Findings." Regional Studies, Vol. 27, No. 4, 1993, 327-40.

Lansing, J. B., and E. Mueller. The Geographic Mobility of Labor. Ann Arbor: Michigan Survey Research Center, 1967.

Polachek, Solomon W., and W. Stanley Siebert. The Economics of Earnings. Cambridge: Cambridge University Press, 1993.

Schlottmann, Alan M., and Henry W. Herzog, Jr. "Employment Status and the Decision to Migrate." Review of Economics and Statistics, Vol. 63, 1981, 590-8. Schwartz, A. "Migration, Age, and Education." Journal of Political Economy, Vol. 84, 1976, 701-19.

Seater, John J. "Job Search and Vacancy Contacts." American Economic Review, June 1979, Vol. 69, 411-19.

Sullivan, Teresa A. Marginal Workers, Marginal Jobs. Austin: The University of Texas Press, 1978.

Trussell, James, and Toni Richards. "Correcting For Unmeasured Heterogeneity in Hazard Models Using the Heckman-Singer Procedure." Sociological Methodology. San Francisco: Jossey Bass, 1985, 242-276.

U.S. Department of Commerce. Survey of Income and Program Participation Users' Guide. Washington, DC: Bureau of the Census, 1991.

Zippay, Allison. From Middle Income to Poor: Downward Mobility Among Displaced Steelworkers. New York: Praeger, 1991. 